\title{
GENERAL
}

\section{HEALTH BEHAVIOUR OF ELDERLY PATIENTS WITH HEART FAILURE IN POLAND ASSOCIATED WITH PHARMACOTHERAPY AND NON-PHARMACOLOGICAL TREATMENT}

\author{
MAGDALENA MAKAREWICZ-WUJEC*, EWELINA JANAS \\ and MAŁGORZATA KOZŁOWSKA-WOJCIECHOWSKA \\ Department of Clinical Pharmacy and Pharmaceutical Care, \\ Medical University of Warsaw Banacha 1, 02-097 Warsaw, Poland
}

\begin{abstract}
Introduction. In Poland, it is estimated that HF is observed in approximately 0,7 million patients. The aim of the study was to assess health behaviour in geriatric patients diagnosed with HF regarding pharmacotherapy and non-pharmacological treatment. Material and methods. The study group comprised 72 patients with diagnosed HF, over $65 \mathrm{y}$. The study was performed using a questionnaire survey including 20 closed-ended questions. Results. The mean number of medicinal products prescribed by physicians for the treatment of HF and other diseases was $6.59 \pm 1.8 .50 \%$ of subjects were additionally taking medications and supplements for self-treatment, $63 \%$ declared they managed to take medications prescribed on their own. A diet is followed only by $50 \%$, but only $18 \%$ limit their sodium intake. $46 \%$ still consume alcohol, and $10 \%$ of still smoke cigarettes. $46 \%$ declared the use of body weight monitoring, but none of them measured their body weight every day. Conclusion. Health behaviour of geriatric patients with HF in Poland indicates their low compliance with medical guidelines and it may explain a high hospitalisation rate and increasing costs of treatment.
\end{abstract}

Keywords: Health behaviour, adherence, elderly patients, heart failure

Heart failure is a chronic circulatory disease that is observed especially frequently in the elderly, and its mortality and hospitalisation rates are high (1). Epidemiological data indicate a growing number of patients with heart failure in the population of highly developed countries. In Europe, it affects $1-2 \%$ of the adult population, and in the $70+$ population, the rate is even above $10 \%$ (2). In Poland, it is estimated that HF is observed in approximately 0,7 million patients and has become the leading cause of hospitalisation in patients older than 65 years (3). In Poland, approximately $3.2 \%$ of health care resources are spent on the diagnosis and treatment of $\mathrm{HF}$, and hospitalisation accounts for the majority of costs (4). In Northern America and Western Europe, estimated expenses associated with care for patients with HF are approximately $1-3 \%$ of all health care expenses (5).

Heart failure is often misdiagnosed and mistreated in the elderly. Both patients and physicians often interpret symptoms of HF as symptoms associated with older age (6). According to the current guidelines, optimum treatment of heart failure includes appropriate diagnostic tests, use of effective pharmacotherapy and training regarding selfmonitoring, including monitoring of symptoms (such as swelling monitoring based on the body weight monitoring), education with regard to physical exercises and a limited intake of salt (7). Daily body weight monitoring combined with entries in a diary results in a lower rate of hospitalisations resulting from this disease (8), similarly as strict compliance with a restriction to limit the salt diet intake (9).

According to the literature adherence to pharmacotherapy guidelines among elderly patients with $\mathrm{HF}$, and the mean age of 70 years, is between $10 \%$ and $99 \%$ (10). Patients with heart failure are especially at risk for non-adherence because of their age, coexisting diseases and high costs of treatment (11, 12). Low adherence to medical guidelines among patients with HF leads to a higher risk of mortality and rehospitalisation $(13,14)$. Moreover, treatment costs are also higher (15).

\footnotetext{
* Corresponding author: e-mail: magdalena.wujec@wum.edu.pl
} 
The aim of the study was to assess health behaviour in geriatric patients diagnosed with heart failure that is associated with pharmacotherapy and non-pharmacological treatment and to assess the adherence to guidelines regarding patients' selfmonitoring with regard to body weight measurements and compliance with non-pharmacological guidelines.

\section{EXPERIMENTAL}

The study was performed using a questionnaire survey in a group of geriatric patients with heart failure. The study inclusion criteria were the age $>65$ years and a diagnosis of heart failure. The study exclusion criterion included confirmed cognitive impairment. The survey was performed as a direct

Table 1. Characteristics of the study group.

\begin{tabular}{|c|c|}
\hline \multicolumn{2}{|c|}{ Study group $(n=72)$} \\
\hline Age & $74 \pm 6.5$ years \\
\hline Women/men $(\%)$ & $34 / 38(47 \% / 53 \%)$ \\
\hline NYHA class (I/II/III/IV) & $(10 \% / 37 \% / 43 \% / 10 \%)$ \\
\hline Duration of $\mathrm{HF}$ & $11 \pm 8$ years \\
\hline \multicolumn{2}{|c|}{ HF aetiology } \\
\hline Ischaemic heart disease & $23 \%$ \\
\hline Arterial hypertension & $33 \%$ \\
\hline Ischaemic heart disease + arterial hypertension & $29 \%$ \\
\hline Valve defects & $4 \%$ \\
\hline Cardiomyopathies & $7 \%$ \\
\hline Other & $4 \%$ \\
\hline \multicolumn{2}{|c|}{ Coexisting diseases } \\
\hline Number of diseases per patient & $2.6 \pm 1.2$ \\
\hline Patients with $0 / 1 / 2 / 3$ or more coexisting diseases & $3 \% / 15 \% / 32 \% / 50 \%$ \\
\hline Diabetes mellitus & $24 \%$ \\
\hline Renal diseases & $10 \%$ \\
\hline Prostate diseases & $11 \%$ \\
\hline Lung diseases & $13 \%$ \\
\hline Hyperlipidaemia & $54 \%$ \\
\hline Joint diseases, RA, gout & $21 \%$ \\
\hline Depression & $6 \%$ \\
\hline CNS diseases, epilepsy & $15 \%$ \\
\hline Arterial hypertension & $65 \%$ \\
\hline Ulcer disease & $22 \%$ \\
\hline \multicolumn{2}{|c|}{ Pharmacotherapy of HF } \\
\hline Angiotensin-converting enzyme inhibitors & $78 \%$ \\
\hline Beta-adrenolytics & $79 \%$ \\
\hline Mineralocorticoid receptor antagonists & $24 \%$ \\
\hline AT1 receptor antagonists & $15 \%$ \\
\hline Loop diuretics & $24 \%$ \\
\hline Thiazide diuretics & $31 \%$ \\
\hline Digitalis glycosides & $6 \%$ \\
\hline Nitrates & $6 \%$ \\
\hline Potassium & $46 \%$ \\
\hline
\end{tabular}


Table 2. Pharmacotherapy of coexisting diseases.

\begin{tabular}{|l|c|}
\hline \multicolumn{2}{|c|}{ Medicinal products used to treat coexisting diseases } \\
\hline Acetylsalicylic acid & $39 \%$ \\
\hline Anticoagulant agents & $35 \%$ \\
\hline Anti-arrhythmic agents and calcium channel blockers & $44 \%$ \\
\hline Statins & $49 \%$ \\
\hline Insulin & $8 \%$ \\
\hline Antidiabetic agents & $17 \%$ \\
\hline Neutralising agents, PPI, H1 receptor blockers & $25 \%$ \\
\hline Bronchodilators & $11 \%$ \\
\hline Inhaled glucocorticosteroids & $13 \%$ \\
\hline Psychostimulating agents & $15 \%$ \\
\hline Anti-depressants & $11 \%$ \\
\hline Anti-epileptics & $1 \%$ \\
\hline Hypnotics and anxiolytics & $18 \%$ \\
\hline Opioid analgesics & $4 \%$ \\
\hline NSAIDs & $11 \%$ \\
\hline Thyroid hormones & $11 \%$ \\
\hline Cardioprotective agents (omega 3 acids, cyanocobalamin) & $6 \%$ \\
\hline Antibiotics & $3 \%$ \\
\hline Allopurinol & $8 \%$ \\
\hline Alpha-blockers and medicinal products used to treat prostate hypertrophy & $11 \%$ \\
\hline Chondroitin, glucosamine & $6 \%$ \\
\hline
\end{tabular}

Table 3. Self-treatment with plant-derived products, analgesics, dietary supplements, and homeopathic preparations.

\begin{tabular}{|l|c|}
\hline \multicolumn{2}{|c|}{ Products used for self-treatment } \\
\hline St John's wort & $7 \%$ \\
\hline Ginkgo biloba & $1 \%$ \\
\hline Garlic & $28 \%$ \\
\hline Echinacea & $4 \%$ \\
\hline OTC analgesic agents & $17 \%$ \\
\hline Vitamin preparations & $20 \%$ \\
\hline Mineral preparations & $17 \%$ \\
\hline Homeopathic preparations & $1 \%$ \\
\hline
\end{tabular}

interview with a patient, without any time restrictions. The above goal was sought by creating a specific research tool - an original questionnaire consisting of 20 closed-ended questions: one choice and yes/no. In some questions about the amount of cigarettes smoked, the amount of alcohol consumed, type of diet, frequency of weight control open space was left for free comments. The questionnaire was validated in a focus group of 10 people over 65 years of age. All patients were asked to bring to the interview, list of taking medications and dietary supplements. The survey was completely anonymous and surveyed patients gave their voluntary consent for participation. The study was approved by the 
Bioethics Committee of the Medical University of Warsaw.

72 patients, including 34 men and 38 women diagnosed with heart failure based on the ESC criteria (year), were enrolled into the study. The study included patients from outpatient clinics of cardiology in 4 cities in the Świętokrzyskie voivodship (1 city of approximately 200,000 residents, 3 cities below 15,000 residents). Table 1 presents characteristics of the study group.

The STATISTICA ver. 10.0 (StatSoft) software was used for statistical analysis. As part of the statistical analysis, the Kruskal-Wallis test for the following independent variables was performed: NYHA class (in four compartments, NYHA class IIV) and duration of heart failure (three time compartments were analysed: 1 - below 5 years; $2-6$ to 10 years and 3 - above 10 years). $p$ and $\chi^{2}$ values for responses to survey questions were included in this test. The p-value $<0.05$ was considered to be statistically significant.

The U Mann-Whitney variance test was used to compare two populations with regard to the age. Two age groups were analysed: 1 - below the age of 75 years; 2 - above the age of 75 years). The $p$ values $<0.05$ were considered to be statistically significant.

\section{RESULTS}

On average, studied patients used 3 medicinal products prescribed for the treatment of heart failure $(3.06 \pm 1.07)$. In the group of surveyed patients, as many as $82 \%$ used other products apart from pharmacotherapy of heart failure: 3 additional products on the average $(3.45 \pm 1.6)$. The use of additional medications depended on the NYHA class (this answer was more common for patients with class III and IV $(\mathrm{p}<0.05)$ and disease duration (this answer was more common in a group of patients diagnosed with heart failure more than 10 years earlier, $\mathrm{p}<$ 0.05 ) in a statistically significant way. In a group of surveyed patients, 90\% declared that a physician managing the treatment for heart failure had been aware of their coexisting diseases and medicinal products used to treat them. The mean number of medicinal products prescribed by physicians for the treatment of heart failure and other diseases was $6.59 \pm 1.8$. Table 2 presents a list of the frequency of use of medicinal products in the pharmacotherapy of coexisting diseases.

Moreover, $50 \%$ of surveyed patients declared the use of other over-the-counter medicinal products as part of their self-treatment (OTC drugs and dietary supplements), apart from those prescribed by physicians. Such products the most commonly included vitamin $(20 \%)$ or mineral $(17 \%)$ supplements, including magnesium and potassium supplements. As many as $17 \%$ of patients used analgesics regularly. Only $1 \%$ of patients used homeopathic preparations. The use and type of OTC products depended on the sex: women used such products more commonly compared to men $(\mathrm{p}<0.05)$. The mean number of all medications (prescribed by physicians, OTC products) and dietary supplements was $7.66 \pm 2.1$. Table 3 presents the frequency of use of products used for self-treatment.

$63 \%$ of subjects declared they managed to take medications prescribed on their own. The remaining $37 \%$ of subjects were helped by a partner, children, caregiver or nurse. The statistical analysis showed that the need for help during treatment was associated with age $(p<0.05)$, NYHA class $(p<0.05)$ and disease duration $(\mathrm{p}<0.005)$. Table 4 presents an analysis of health behaviour associated with pharmacotherapy. The study did not establish significant correlations between the number of taking preparations and the omission of a dose of medications. However, in the group of patients who omit doses of medications, the mean number of all taking medications and supplements was higher than in rest of the group $(8.65 \pm 2.3$ vs. $7.35 \pm 2.0)$. Table 5 presents the frequency of answers regarding self-monitoring and compliance with non-pharmacological guidelines.

\section{DISCUSSION}

Adherence is considered to be a necessary factor in order to obtain positive outcomes of treatment in HF (16).

Terms of adherence and non-adherence, and compliance and non-compliance have various definitions in the literature, therefore, it is extremely difficult to compare study results. Moreover, various assessment methods are used: assessment of data from pharmacies, use of modern technologies such as electronic monitoring or use of various survey questionnaires during patients' interviews. Treatment of a patient with heart failure is extremely complex and is based on guidelines regarding pharmacotherapy and non-pharmacological guidelines regarding a lifestyle (17). Adherence to pharmacotherapy is usually low in the elderly (below 45\%) (18). To a large extent, it is a result of polypharmacy. Polypharmacy may lead to a reduction of the adherence rate to $35 \%$ in the elderly taking at least 4 medications (19). In this study, patients were typically taking 6 medications prescribed by 
physicians (used together in the treatment of heart failure and coexisting diseases), and therefore the risk of non-adherence was extremely high. To make the situation worse, almost $50 \%$ of subjects were additionally taking medications and supplements for self-treatment, such as analgesics, herbal products and mineral products that may have various drug interactions.

Table 4. Patients' behaviour related to pharmacotherapy.

\begin{tabular}{|c|c|}
\hline \multicolumn{2}{|c|}{ Self-dosing with medications } \\
\hline Yes & $63 \%$ \\
\hline No & $37 \%$ \\
\hline \multicolumn{2}{|c|}{ Omission of a dose of medication } \\
\hline Often & $1 \%$ \\
\hline Sometimes & $18 \%$ \\
\hline Very rarely & $39 \%$ \\
\hline Never & $42 \%$ \\
\hline \multicolumn{2}{|c|}{ Management of dose omission } \\
\hline I take the forgotten dose as soon as possible & $29 \%$ \\
\hline I take a double dose with the next dose & $1 \%$ \\
\hline I omit the forgotten dose & $70 \%$ \\
\hline \multicolumn{2}{|c|}{ Omission of doses on purpose } \\
\hline Yes, when I feel better/worse & $19 \%$ \\
\hline No & $81 \%$ \\
\hline \multicolumn{2}{|c|}{ Changing the dose oneself } \\
\hline Often & $0 \%$ \\
\hline Sometimes & $8 \%$ \\
\hline Very rarely & $18 \%$ \\
\hline Never & $74 \%$ \\
\hline \multicolumn{2}{|c|}{ Informing a physician about changing the dose } \\
\hline Yes & $25 \%$ \\
\hline No & $75 \%$ \\
\hline \multicolumn{2}{|c|}{ Consulting a dose change with a pharmacist } \\
\hline Yes & $18 \%$ \\
\hline No & $82 \%$ \\
\hline \multicolumn{2}{|c|}{ Taking medications with fluids } \\
\hline Tea & $50 \%$ \\
\hline Coffee & $0 \%$ \\
\hline Water & $31 \%$ \\
\hline Milk & $3 \%$ \\
\hline Juice & $0 \%$ \\
\hline Herbal infusion & $0 \%$ \\
\hline I do not drink when taking medications & $11 \%$ \\
\hline Other beverages & $5 \%$ \\
\hline \multicolumn{2}{|c|}{ Method to identify medication } \\
\hline I always check the medication name on the package & $38 \%$ \\
\hline I identify by the package but I do not check the name & $39 \%$ \\
\hline By the tablet colour & $11 \%$ \\
\hline By the tablet shape & $12 \%$ \\
\hline
\end{tabular}


This study indicates that patients often change medication dosage on their own. 26\% declared changing medication dosage on their own, and $19 \%$ of subjects typically change medication dosage on their own if they feel better or worse. However, as many as $58 \%$ of patients forget to take medications regularly, and this is worrying. In this group, $70 \%$ of patients declared they did not take a medication dose that had been forgotten, and $29 \%$ took such a dose as soon as they remembered. This way of treatment may lead to reduced levels of the active substance, consequently, to lack of treatment efficacy or increased levels of the active substance in the patient's body resulting in adverse events. In geriatric patients, a problem of medication posology is also associated with the correct identification of medications. Only $38 \%$ of patients confirmed they had been checking the medication name on the package prior to dosing. It is worrying to observe that $11 \%$ of patients identified medications by the

Table 5. Patients' behaviour related to a lifestyle and self-monitoring.

\begin{tabular}{|c|c|c|}
\hline \multicolumn{3}{|c|}{ Compliance with dietary guidelines recommended by a physician } \\
\hline Yes & & $50 \%$ \\
\hline$\bullet$ & Diet low in sugar & $13 \%$ \\
\hline$\bullet$ & Diet low in fat & $13 \%$ \\
\hline$\bullet$ & Diet low in sugar and fat & $7 \%$ \\
\hline$\bullet$ & Diet low in salt & $7 \%$ \\
\hline$\bullet$ & Diet low in salt and fat & $11 \%$ \\
\hline \multicolumn{3}{|c|}{ Alcohol consumption } \\
\hline Ofte & & $0 \%$ \\
\hline Som & & $19 \%$ \\
\hline$\bullet$ & One beer or glass of wine per day & $7 \%$ \\
\hline$\bullet$ & 2-3 beers, 2-3 glasses of wine or 2-3 shots of vodka per day & $11 \%$ \\
\hline$\bullet$ & More & $1 \%$ \\
\hline Very & & $27 \%$ \\
\hline I do & alcohol & $54 \%$ \\
\hline \multicolumn{3}{|c|}{ Cigarette smoking } \\
\hline Yes & & $10 \%$ \\
\hline$\bullet$ & one pack per 3-5 days & $6 \%$ \\
\hline$\bullet$ & pack a day & $4 \%$ \\
\hline I do & & $90 \%$ \\
\hline \multicolumn{3}{|c|}{ Body weight monitoring } \\
\hline Yes & & $46 \%$ \\
\hline$\bullet$ & More than once a week & $6 \%$ \\
\hline$\bullet$ & Once every 2 weeks & $7 \%$ \\
\hline$\bullet$ & Once a month & $19 \%$ \\
\hline$\bullet$ & Every 2 months & $10 \%$ \\
\hline$\bullet$ & Every 6 months & $4 \%$ \\
\hline I do & itor & $54 \%$ \\
\hline \multicolumn{3}{|c|}{ Do you keep the body weight diary? } \\
\hline Yes & & $3 \%$ \\
\hline No & & $97 \%$ \\
\hline \multicolumn{3}{|c|}{ Knowing what to do when the body weight increases by more than $2 \mathrm{~kg}$ within 3 days } \\
\hline Yes & & $19 \%$ \\
\hline No & & $81 \%$ \\
\hline
\end{tabular}


colour, and $12 \%$ by the tablet shape, therefore errors are easy to make. A method of how a medication is taken also affects changes in the absorption and distribution of medicinal products in the body. Unfortunately, only $31 \%$ of surveyed patients said they had been taking medications with water. As many as $50 \%$ of patients took medications with tea, $3 \%$ with milk, and it may be associated with a risk of food-drug interactions.

Geriatric patients do not often comply with physician's guidelines because of a too complex treatment regimen, long treatment duration or introduction of constant changes that are difficult to be remembered by the elderly. Changes in treatment are caused by, e.g. exacerbation of disease symptoms, patient's disability, progression rate or need to treat coexisting diseases, such as mental limitations or depression. $(20,21)$.

The problem of adherence is also associated with non-pharmacological guidelines that are usually regarded by patients as difficult to introduce or hardly significant. Patients are required to change their previous habits and to introduce new ones such as a limited intake of salt and fluids, tobacco smoking cessation, reduced alcohol consumption, performing physical exercises of moderate activity and daily body weight monitoring (21). Such guidelines are not welcomed by patients as they change their previous and organised lifestyles.

Based on literature data despite continuous education patients do not comply with guidelines regarding, for example, a limited intake of sodium adherence $13-75 \%(22,23)$, a reduced intake of fluids - adherence below $23 \%$ (24) or daily body weight monitoring -adherence $12-79 \%$ (25). Such behaviour leads to reduced treatment efficacy and additionally, it is one of the most important factors responsible for exacerbation of the patient's condition (21).

This study confirms these findings. A diet recommended by a physician is followed only by $50 \%$ of patients, but only $18 \%$ of them limit their sodium intake. $46 \%$ of patients still consume alcohol, and $10 \%$ of patients still smoke cigarettes. A change of old dietary habits in the elderly is difficult, and when it is poorly managed it may have negative consequences such as a reduced calorie intake with a diet or an insufficient protein intake resulting in further health complications (21). It is also difficult to comply with other non-pharmacological guidelines, such as those related to physical activity, therefore education regarding non-pharmacological changes should be managed by specialists in a multi-specialist team including not only cardiologists but also nurses spe- cialising in HF treatment, general practitioners and other experts such as dieticians, physiotherapists and pharmacists (7).

It is worrying to observe that body weight measurements are not used as a method to control disease symptoms. Only $46 \%$ of patients declared the use of body weight monitoring, but none of them measured their body weight every day. $19 \%$ of surveyed patients declared performing one body weight measurement per month. As many as 97\% of patients do not keep a body weight diary. Taking into account such findings there is a question whether this situation has been caused by a lack of appropriate information regarding the significance of this measurement to monitor this disease that should have been provided by a physician.

Findings indicate that patients do not comply with guidelines regarding their lifestyle and selfmonitoring, probably because they think that pharmacotherapy is sufficient. Patient's self-monitoring, e.g. daily body weight monitoring, may reduce the hospitalisation rate for a given patient. According to the ESC recommendations of 2016, a patient should be aware that a sudden body weight increase by 2-3 $\mathrm{kg}$ is a result of water retention in the body and it is an indication for urgent consultation with a physician or an indication to increase a diuretic dose (7).

Consequences of a lack of compliance with pharmacological or non-pharmacological guidelines are extremely serious. The study by van der Wal et al. (10) showed that as many as $21-64 \%$ of studied patients required hospitalisation for reasons mentioned above.

Poor patients' adherence is a result of many factors, including economic situation, health care system, patient's health status, therapy used. A majority of these factors is significant for elderly patients and consequently, they are especially at risk of non-adherence (21). Additionally, the social and economic status of geriatric patients is usually low, they often live alone and are not supported by society, therefore their adherence is affected. High costs of treatment are also a common cause of non-adherence $(20,26)$. Also, psychosocial factors have major implications on adherence to therapy (27). Another important aspect is a lack of positive relations between a physician, pharmacist and other health care specialists and a patient and the fact that educational brochures are not suitable for elderly patients (28). Currently, the treatment of HF in elderly patients is characterized by widespread under-utilization of the recommended therapies (29). According to studies, in many European countries, except for such countries like Scotland or Holland, a 
general practitioner is hardly involved in the basic care over patients with heart failure, similarly as in Poland (30).

Summing up, it can be concluded that the health behaviour of geriatric patients with heart failure in Poland indicates their low compliance with medical guidelines what may explain a high hospitalisation rate and increasing costs of treatment. Therefore it is necessary to create an interdisciplinary programme for geriatric patients and their caregivers as part of the health care system so as it would allow for more effective education regarding the use of medicinal products, self-monitoring and nonpharmacological guidelines.

\section{Study limitations}

The relatively small number of patients participating in the study might have affected the power of statistical analysis of the results. The study did not include an assessment of the impact of socio-economic factors on the health behaviour of patients.

\section{Conflicts of interest}

None.

\section{REFERENCES}

1. Ziaeian B., Fonarow G.C.: Nat. Rev. Cardiol. 13, 368 (2016).

2. Laribi S., Aouba A., Nikolaou M., Lassus J., Cohen-Solal A. et al.: Eur. J. Heart Fail. 14, 234 (2012).

3. Rywik T.M., Kołodziej P., Targoński R., Fedyk-Łukasik M., Nowicka A. et al.: Kardiol. Pol. 69, 24 (2011).

4. Czech M., Opolski G., Zdrojewski T., Dubiel J.S., Wizner B. et al.: Kardiol. Pol. 71, 224 (2013).

5. Ponikowski P., Anker S.D., AlHabib K.F., Cowie M.R., Force T.L. et al.: ESC Heart Fail. 1, 4 (2014).

6. Cheng J., Nayaer M.: Am. J. Ger. Pharm. 7, 233 (2009).

7. Ponikowski P., Voors A.A., Anker S.D., Bueno H., Cleland J.G. et al.: Eur. J. Heart. Fail. 18, 891 (2016).

8. Jones C.D., Holmes G.M., De Walt D.A., Erman B., Brocksou K. et al.: J. Card. Fail. 18, 576 (2012)

9. Fonarow G.C., Abraham W.T., Albert N.M., Stough W.G., Gheorghiade M. et al.: Arch. Intern. Med. 168, 847 (2008).
10. van der Wal M.H., Jaarsma T., Van Veldhuisen D.J.: Eur. J. Heart. Fail. 7, 5 (2005).

11. Havranek E.P., Maoudi F.A., Westfall K.A., Wolfe P., Ordin D.L. et al.: Am. Heart. J. 143, 412 (2002).

12. Masoudi F.A., Baillie C.A., Wang Y., Bradford W.D., Steiner J.F. et al.: Arch. Intern. Med. 165, 2069 (2005).

13. Albert N.M.: Crit. Care Nurse 28, 54 (2008).

14. Betihavas V., Newton P.J., Frost S.A., Alexandrou E., Macdonald P.S. et al.: Heart Lung Circ. 22, 179 (2013).

15. Ho P.M., Bryson C.L., Rumsfeld J.S.: Circulation 119, 3028 (2009).

16. Fitzgerald A.A., Powers J.D., Ho P.M., Maddox T.M., Peterson P.N. et al.: J. Card. Fail. 17, 664 (2011).

17. Gandhi J., McCue A., Cole R.: Curr. Heart Fail. Rep. 13, 77 (2016).

18. Giardini A., Martin M.T., Cahir C., Lehane F., Menditto E. et al.: Aging Clin. Exp. Res. 28, 371(2016).

19. Maher R.L., Hanlon J.T., Hajjar E.R.: Expert Opinion Drug Saf. 13, 57 (2014).

20. van der Wal M.H., Jaarsma T., Moser D.K., Veeger N.J., van Gilst W.H. et al.: Eur. Heart J. 27, 434 (2006).

21. van der Wal M.H., Jaarsma T.: Int. J. Cardiol. 25, 203 (2008).

22. Schwarz K.A., Elman C.S.: Heart Lung 32, 88 (2003).

23. Moser D.K., Doering L.V., Chung M.L.: Am. Heart J. 150, 984 (2005).

24. Jaarsma T., Abu-Saad H.H., Dracup K., Halfens R.: Scand. J. Caring Sci. 14, 112 (2000).

25. Stromberg A., Martensson J., Fridlund B., Levin L.A., Karlsson J.E.: Eur. Heart J. 24, 1014 (2003).

26. Artinian N., Magnan M., Sloan M., Lange M.P.: Heart Lung 31, 161 (2002).

27. Bader F., Atallah B., Brennan L.F., Rimawi R.H., Khalil M.E.: Heart Fail. Rev. 22, 219 (2017).

28. De G.S., Steeman E., Leventhal M.E., MahrerImhof R., Hengartner-Kopp B. et al.: Eur. J. Cardiovasc. Nurs. 3, 263 (2004).

29. Scorcu G., Pilleri A.: Monaldi Arch. Chest. Dis. 88, 948 (2018).

30. Luttik M.L., Brons M., Jaarsma T., Hillege H.L., Hoes A. et al.: Neth. Heart J. 20, 307 (2012).

Received: 2.07. 2018 